\title{
Analysis of College English Online Test and Language Teaching
}

\section{Jing Wu}

Wuzhou University, Wuzhou,Guangxi,543002, China

Thesis for the Project: From Gold Course to Gold Class-A Study of Building successful Teaching Group for College En glish in Wuzhou University (Wyjg2019A080)

Abstract: In order to adapt to the current Internet information environment, college English teaching also needs to carry out corresponding online teaching courses based on the actual situation, so as to make college English teaching more flexible and improve students' enthusiasm for learning English. English online testing can help teachers Deepen the understanding of students, and continuously improve and revise the teaching methods to strengthen the effectiveness of language teaching. This article attempts to analyze the relationship between online testing and language teaching in English universities based on the actual teaching situation and current online course development, in order to promote the sound development of college English teaching.

Keywords: university English online test Language teaching

In traditional English teaching, testing is an indispensable part. It can help teachers understand the actual learning situation of students, give targeted explanations on the problems that students lack in teaching, and help students improve their English proficiency quickly., Testing and teaching are inseparable. With the rise of online teaching, teachers are constantly improving the online English test. Because of the different environments, the traditional written test cannot be used, so the specific test methods and content must be changed. Based on many years of English teaching experience, the author analyzes in detail the necessity of online English testing in language teaching, and expounds some enlightening effects of online testing on language teaching, hoping to improve the level of English teaching in Chinese universities and improve students' English Comprehensive ability.

\section{The necessity of online English test in language teaching}

Nowadays, the convenience brought by the Internet has a great influence on the education and teaching of various subjects in current universities. Students use the Internet to find materials, take online courses, and learn the subject knowledge they are interested in. These have greatly expanded the contemporary college students Knowledge and deepen the students' cognitive level of various subjects, which is also true for English teaching, so it is very necessary to do an online test of English in English language teaching.

First of all, online English tests can make students more flexible in learning. Students can conduct self-tests and summaries at any time during the English learning process. They do not need to take the test within the specified time according to the traditional teaching mode, and can select the test content in a targeted manner, so that students can learn more refined and improve students' Learning efficiency.

Secondly, the English online test can enrich the test content. The traditional English test is basically written test and listening comprehension, and there is no effective way to test the students' oral ability. However, the online online test can use voice software to examine the students' pronunciation, which is an upgrade on the basis of the original test. Effectively make up for the shortcomings of the current English language test, allowing students to truly improve their

Copyright $\odot 2020$ Jing Wu

doi: 10.18282/le.v9i6.1339

This is an open-access article distributed under the terms of the Creative Commons Attribution Non-Commercial License

(http://creativecommons.org/licenses/by-nc/4.0/), which permits unrestricted non-commercial use, distribution, and reproduction in any medium, provided the original work is properly cited. 
English language expression skills and apply what they have learned.

The online test of English again can improve the teaching efficiency of teachers. The online test is more flexible. The system has an automatic judgment program. It does not require teachers to spend a lot of time in judging and studying. Students and teachers can know the test results immediately after the test, and analyze and follow up on the test results as quickly as possible. Greatly improve the teacher's English teaching efficiency, so that teachers can put more energy on the innovation of teaching content.

Finally, the online English test allows students to clearly understand their own growth and improve their confidence in learning. Compared with traditional tests, students and teachers do not have the energy to summarize after the fact, but the previous test can record and store the learning process of students at various stages, and students can regularly review and review what they have encountered during their learning process. Frustration and self-growth, this way of looking back at old photos greatly increases the confidence of students to continue learning and makes English language learning more efficient.

\section{The enlightening effect of online testing on language teaching}

The implementation of online English testing is the inevitable result of the current society and the development of the times. In this process, it can be compared with traditional English language teaching, reflect on the deficiencies in the past education, and strive to achieve the organic combination of online and offline education, and comprehensively improve our country Effectiveness of English language teaching.

First of all. The English online test system is still constantly being upgraded and improved. The most obvious change is the emergence of the inherent question bank and random question bank. During the online test of students on the Internet, the system will pass certain tests based on the content browsed by the students and past test content. The algorithm generates a personalized test question. In addition to the inherent questions designed by the teacher, there are also some questions randomly generated according to the students' own conditions. This makes the test more humane and allows teachers and students to find more accurately Its own shortcomings are also the personalized teaching goals that traditional teaching hopes to achieve.

Secondly, in addition to the quality of the questions, what affects the effect of online testing is the consideration of the fairness of the test. Due to some technical reasons, the fairness of the online test becomes more difficult to control. In order to ensure the effectiveness of education and teaching, the first thing to do is Improve teachers' professional quality, and then use this to guide students to improve their self-consciousness and self-discipline. It is necessary to make it clear that the purpose of the test is not test scores, but to understand their own learning status through the test, find problems in learning, and let students start from the beginning To develop a good habit of standardized answering questions, so that students can truly have an open and free learning environment. On the basis of improving students' academic performance, they also subtly cultivate good behaviors and morals of honesty and trustworthiness. This is also the correct way to teach and educate people. the way.

Finally, online testing can effectively change the current English language teaching methods. Schools and society should vigorously promote online testing, and provide maximum support in terms of technology and policies. Technically, the online test can integrate the listening, reading, writing, translation and other test content of the traditional test, and make the questions more flexible. It can also complement the short-board oral test of the traditional test. Therefore, the online test can effectively improve The students' oral communication ability makes language teaching more in line with actual requirements. In terms of policy, the current society is already an extremely welldeveloped information society. People's online communication can eliminate time and space constraints, and make learning and communication more free. Whether it is resource utilization or talent information exchange, online learning and Tests have a very positive effect on the current social development. Educational departments should gather social forces to increase investment in online teaching platforms, gradually improve online teaching, integrate online teaching with actual teaching, and improve the quality of language teaching in China.

\section{Concluding remarks}


All in all, although online testing is a new type of testing method in college English teaching, its development prospects and importance to the reform of English language education are very promising. Teachers should constantly improve the types of questions in online testing and use online Tests are used to make up for the shortcomings of traditional teaching tests, combining online and offline teaching closely, and effectively improving the quality of English language teaching in China.

\section{References}

1. Lei Yanyan. On Language Testing and College English Teaching[J]. Occupational Time and Space, 2013, 009(011):73-74,88.

2. Liu Ying. Analysis of College English Test Reform [J]. Science and Technology Information, 2006, 000(027): 177177.

3. Tan Shihui, Gao Shuling. Analysis of the relationship between college English testing and classroom teaching [J]. Shaanxi Education: Higher Education Edition, 2011, 000(011): 62-63. 